\title{
Aspectos éticos y jurídicos de la comercialización de partes separadas del cuerpo humano
}

Salvador D. Bergel

\section{Resumen}

El trabajo expone reflexiones sobre la mercantilización del cuerpo humano, sus partes y sus productos. Centralmente toma el caso particular de las células humanas, que en sí no presenta mayores diferencias con otros, como el de los genes, proteínas, secuencias de genes, medicamentos biológicos etc., por cuya razón las conclusiones a las que arribemos deben reconocer un cierto grado de generalización. En las consideraciones finales se recuerda los enormes cambios en la idea de la comercialización del cuerpo humano, que evocaba la esclavitud y se hay pasado muy rápidamente a una situación donde ella está ligada a los progresos de la Medicina, rematando a la conclusión con la advertencia que el debate no puede quedar circunscripto a los derechos de propiedad industrial en la medida en que se encuentran comprometidos intereses de primer nivel como la salud y la dignidad humana.

Palabras-clave: Violaciones de los derechos humanos. Cuerpo humano - Comercio. Personas. Patentes. Leyes.

\section{Resumo}

\section{Aspectos éticos e jurídicos da comercialização de partes separadas do corpo humano}

Este trabalho expõe reflexões sobre a mercantilização do corpo humano, suas partes e produtos. Centralmente toma-se o caso particular das células humanas que, em si, não apresentam maiores diferenças com outros organismos como os genes, proteínas, sequência de genes, medicamentos biológicos etc., razão pela qual as conclusões as quais se chega podem ser em certa medida generalizáveis. Nas considerações finais são lembradas as enormes mudanças na ideia da comercialização do corpo humano, que evocava a escravidão e passou muito rapidamente a uma situação ligada ao progresso da medicina. Finalizando, conclui com a advertência de que o debate não pode ficar circunscrito aos direitos de propriedade industrial, uma vez que compromete interesses de primeiro nível, como a saúde e a dignidade humana.

Palabras-chave: Violações dos direitos humanos. Corpo humano - Comércio. Pessoas. Patentes. Leis.

\begin{abstract}
Ethical and legal aspects of commercialization of individual human body parts

This paper presents reflections on the commodification of the human body, its parts and products. It centrally takes the particular case of human cells, which in itself presents no major differences with other organisms, such as genes, proteins, gene sequences, biological medications, etc, for which reason the conclusions which can be reached, may be generalizable in some degree. In the final considerations the enormous changes in the idea of commercialization of the human body are reminded, which evoked slavery and passed very quickly to a situation linked to medical progress. The conclusion with the warning that the debate can not be confined to industrial property rights to the extent that compromises interests in the first level such as health and human dignity.

Key words: Human rights violations. Human body - Commerce. Persons. Patents. Laws.
\end{abstract}

Doutor s.bergel@zbv.com.ar - Cátedra Unesco de Bioética en la Universidad de Buenos Aires, Buenos Aires/CF, Argentina.

Correspondência

Florida 537 Piso $18^{\circ} \mathrm{C} 1005$ AAK. Cidade Autônoma de Buenos Aires/CF, Argentina.

Declara não haver conflito de interesse. 
Desde siempre, y tal vez sin poder ubicar con precisión su origen, se consideró que el cuerpo humano estaba fuera del comercio, fuera del mercado. Razones religiosas y éticas obraron para sustentar tal afirmación. La identificación del cuerpo con la persona y el reconocimiento de la dignidad intrínseca de la condición humana, gravitaron para mantener intangible en el tiempo tal principio. Dahl Rendtorff señala que el cuerpo humano y sus partes pueden verse como algo que afirma su dignidad, como una expresión de la persona humana y de lo que específicamente es propio del hombre. En consecuencia respetar el cuerpo y sus partes es respetar la dignidad humana ${ }^{1}$.

Cuando la evolución de las ciencias biológicas llevó a trabajar y a investigar sobre las partes separadas del cuerpo (incluyendo células, tejidos, genes etc.), se advirtió la necesidad de atribuir a las mismas un estatuto específico. Helgan Kuhse recuerda sobre este particular que desde siempre el cuerpo humano y sus partes han tenido gran importancia, pero en la actualidad lo que cuenta es la utilización de partes humanas en los resultados de los programas médicos y biológicos ${ }^{2}$. Partiendo de la no discutida dualidad para el derecho entre persona y cosa, surgió un debate interesante en torno a la adscripción de las partes del cuerpo a una de tales categorías, o en su caso, sobre la inutilidad de tales categorías para enfrentar el tema en debate.

Recién con el dictado de las leyes francesas de bioética en el año 1994, el principio de la exclusión del cuerpo y de sus partes del comercio adquirió carta de ciudadanía para el derecho. El Código Civil francés en su artículo 16.1 establece que el cuerpo humano, sus elementos y sus productos no pueden ser objeto de un derecho patrimonial ${ }^{3}$, en similar sentido, el Convenio de Oviedo relativo a la Biomedicina y a los Derechos Humanos dedica el Capítulo VII a la prohibición de lucro y utilización de una parte del cuerpo humano ${ }^{4}$; estableciendo en su artículo 21 que el cuerpo humano y sus partes como tales no pueden ser objeto de lucro.

El informe explicativo del referido artículo señala que aplica el principio de la dignidad humana establecido en el preámbulo y en el artículo $1^{\circ}$. El artículo afirma que el cuerpo humano y sus partes como tales no pueden generar un aprovechamiento económico. Bajo esta disposición, los órganos y tejidos, incluyendo la sangre, no pueden ser comprados o vendidos o generar cualquier ganancia financiera a la persona de quien se lo ha extraído o a un tercero, sea un individuo o una corporación.
Estos principios, por otra parte, fueron receptados por la Carta de los Derechos Fundamentales de la Unión Europea (art. 3.2) ${ }^{5}$ y se los ha considerado como uno de los derechos fundamentales de la persona. La patentabilidad del cuerpo en su integridad pareciera ser un tema fuera de debate. A nadie se le puede ocurrir sensatamente a esta altura de los tiempos, comerciar con el cuerpo. En cambio, respecto a las partes separadas del cuerpo, la respuesta no parece tan pacífica.

Un filósofo francés que integró el Comité Nacional de Ética, Lucien Seve ${ }^{6}$, se pregunta al analizar los límites de la persona, no tanto en el tiempo sino en el espacio, es decir cuando pasamos del cuerpo en su integridad a sus partes, más y más pequeñas; si es válido mantener el mismo criterio respecto de la condición que ellos merecen. El cuerpo dividido agrega - no es el individuo. Aquí no existe el ser humano. ¿Hasta qué nivel es sensato reconocer aquí el segmento menor de lo humano y asignarle una dignidad? Llegando a la célula, al gen, en la medida que se borra todo tratamiento específico de humanidad, ¿qué queda aquí de la humanidad? ¿Cómo mantener aquí la distinción cardinal entre la persona y la cosa? Concluye Sève sus reflexiones sosteniendo que debería tomarse en cuenta más su uso social que su expresión biológica.

Por nuestra parte señalamos que la consideración que merecen las partes separadas del cuerpo no tiene relación, o al menos una relación relevante, con el tamaño físico de la parte de la cual se trate. Traigo a colación el gen o la célula que en su tamaño minúsculo encierran notas esenciales de la vida humana. Ya al tiempo de la sanción de las leyes francesas de bioética de 1994 7 , la comercialización de las partes del cuerpo constituía una realidad palpable. Es que un órgano, un tejido, los genes, las células, pueden en esta nueva realidad servir para fines utilitarios y esto despertó el interés económico por su posesión o comercialización, lo que llevó a imaginar la aplicación de nuevos criterios jurídicos que los justifican.

En esencia consideramos que el cuerpo en su integridad, así como sus partes separadas responden a una misma realidad, lo que autoriza a aplicar similares principios en cuanto a la consideración y el trato que merecen. Tanto el gen como las células o los tejidos humanos separados han sido parte funcional del cuerpo y no existen argumentos atendibles para que una vez separados sean considerados en forma distinta al cuerpo en su integridad.

Es que, las mismas razones que apartan al cuerpo del mercado, deberían operar respecto de 
las partes separadas del mismo, si es que les reconocemos igual naturaleza humana. Si el cuerpo en su integridad está fuera del comercio, ¿con qué argumentos podría sostenerse que una parte separada por el sólo efecto de su segregación pierde el carácter que se le atribuye al todo? No obstante la razonabilidad de esta postura, lo cierto es que cada vez con más intensidad podemos observar cómo las partes separadas del cuerpo han ingresado al mercado.

Rodotá ${ }^{8}$, insigne jurista y maestro de la bioética, señala que es precisamente la compensación económica lo que revela la inscripción del cuerpo y de la vida al ámbito de la propiedad, abandonando su adscripción exclusiva con la dimensión de la personalidad, respaldada por principios y garantías cualitativamente diferentes y más fuertes. Si el criterio es el mercado - agrega - palabras como igualdad y dignidad quedan desvirtuadas, pierden peso, y con ello se disuelve la autonomía de la persona confinada a la libertad de entrada o salida del mercado.

En el cuadro que presentamos, tomar una parte separada del cuerpo como una "cosa" simple importa autorizar su ingreso al tráfico mercantil, desvirtuando la consideración y el respeto por la dignidad humana que connota el cuerpo; consideración que - tal como lo entendemos- cabe extender a las partes separadas. Aquí, no sólo cabe excluir la comercialización, sino también la patentabilidad de células, líneas celulares, células madre, en tanto la patente de invención tiene un innegable contenido patrimonial, es fruto de réditos económicos y puede ser cedida o licenciada a título oneroso.

Si bien las células no son "personas", atendiendo a la clásica categorización del derecho privado, no puede sostenerse que sean "cosas", sin más agregados. Las células - sostiene Wulpert Lewis ${ }^{9}$ - son la base de cualquier forma de vida. Son muy pequeñas, pero para su tamaño son los objetos más complejos del universo. Esto nos anoticia que cuando hablamos de una célula, no estamos hablando de cualquier cosa, sino de algo esencial para la vida.

Edelman ${ }^{10}$, jurista y filósofo francés, marca las consecuencias que tendría tal adscripción: hay una diferencia drástica entre el hecho de tener un derecho de propiedad sobre el cuerpo y el ser propietario de una persona. Esta tajante diferencia es sin dudas, esencial, si vendiendo mis células me vendiera a mí mismo, yo sería reducido a la esclavitud, si por el contrario mis células son "desechables"; si ellas no son más que cualquier cosa de mí, sin ser mi persona, consecuentemente podría enajenarlas permaneciendo libre. Dicho de otro modo, el solo hecho de formular esa diferencia implica que el individuo era propietario de su cuerpo, que habría que distinguir entre la persona que se sitúa en el orden de la libertad y sus elementos corporales que se sitúan en el orden de las cosas.

Lo anotado nos advierte que la tradicional división jurídica entre persona y cosa se muestra inadaptada a la realidad que nos presentan los aportes de la biología contemporánea. Si atendiendo a esta división binaria concluimos que las partes separadas son simplemente "cosas", sin más agregados, el derecho está autorizando la venta y comercialización de órganos, tejidos, células, etc., lo que a los ojos de cualquier observador luce como inmoral. La mencionada separación entre persona y cosa, que sirvió y sirve a muchos fines para el derecho privado debe considerarse, al menos, que se encuentra en crisis. La categoría persona se refiere exclusivamente al ser humano en su integridad. Las partes separadas no son obviamente "personas". En consecuencia, ¿podría afirmarse que son cosas que están en el comercio?

A primera vista pareciera desatinado, lo que nos lleva a intentar otras vías de aproximación. En esta tarea viene muy al caso el lúcido pensamiento de M. A. Hermitte que hace años postuló la creación de una categoría, la de cosas de origen humano y con finalidad humana ${ }^{11}$ para insertar en su seno las partes separadas del cuerpo y permitir atender en su consideración el respeto a la dignidad humana. De esta forma los órganos, tejidos, células, etc., quedarían fuera del comercio y fuera del mercado, lo que se compadece con una visión más cercana a la consideración de la dignidad que le reconocemos al cuerpo y sus partes.

\section{La propiedad de las células humanas}

El reconocimiento de un derecho de propiedad del hombre sobre los elementos constitutivos del cuerpo es el puente necesario para admitir la comercialización de los mismos. Existe un caso en la jurisprudencia norteamericana, en el que se discutió el derecho que le asistía a un individuo sobre sus propios tejidos y células, el famoso caso Moore. En 1976, John Moore fue atendido por una rara forma de leucemia, patología para la cual el médico que lo atendió, aconsejó extirparle el bazo. En el curso de su posterior tratamiento se constató que Moore producía sustancias liberadas por los linfocitos T: las linfocinas en cantidad muy superior a lo normal. En base a las células del bazo, el facultativo desarrolló una línea celular que patentó en 1981 con el nom- 
bre de "célula MO", cediendo los derechos de la explotación comercial a Genetics Institute y a Sandoz Pharmaceuticals. Al tomar conocimiento de ello, el paciente Moore interpuso una demanda contra el facultativo que comprendía entre otros requerimientos:

- conversión (ilícito que consiste en apoderarse de cosas abandonadas);

- falta de consentimiento informado;

- incumplimiento de la obligación de buena fe en la práctica médica;

- responsabilidad civil.

En base a ello pretendió obtener una compensación económica por la utilización comercial de su línea celular, que generó grandes utilidades a quien la patentó.

La demanda fue rechazada en primera instancia, acogida por el Tribunal de Apelaciones y finalmente rechazada por la Corte Suprema de California. Es importante destacar que la Corte, luego de admitir que el médico había perjudicado a Moore al explotar sin su consentimiento sus líneas celulares, entendió que no cabía hablar, sino limitadamente de un derecho de propiedad sobre partes removidas del cuerpo. Se denegó de esta forma, su derecho a participar en las utilidades y en su explotación, tanto por la sustancial inexistencia de property rights, cuanto por considerar que una compensación económica lesionaría la dignidad humana.

La motivación de la Corte, en opinión de Tallacchini ${ }^{12}$, deja un extraño vacío a propósito de la propiedad de los materiales, porque éstos son objeto de actos no patrimoniales de autonomía, pero por otra parte se precisa que el médico ni siquiera tenía la propiedad de los tejidos, sino sobre los derechos de patentes de invención. Se deja pues sin dirimir la cuestión de las modalidades de la cesiónadquisición de las células, pero con consecuencias diversas para las partes. Nadie tiene la propiedad de los tejidos, pero de este "no derecho" el recurrente no puede sacar ventaja económica alguna mientras el recurrido (el médico) puede obtener una utilidad exclusiva.

De hecho, se adjudican derechos y precisamente son adjudicados a quien posee los instrumentos productivos para lanzar los productos al mercado ${ }^{12}$. Ubicar a los derechos nacidos de la patente en un terreno distinto al del dominio (propiedad civil), constituye una hipocresía. El tribunal dejó sin resolver el que en mi parecer es el tema más relevante del litigio: la existencia o inexistencia de derechos de propiedad sobre las partes separadas del cuerpo.

\section{Células "naturales" y las obtenidas por proce- dimientos técnicos}

El sostenido avance de las ciencias biológicas, llevó a los científicos a trabajar sobre las partes separadas del cuerpo, para modificarlas en función de la búsqueda de resultados directamente utilizables por la medicina, o simplemente para dar un paso de avance en investigaciones que en un futuro puedan contribuir a solucionar problemas sanitarios.

La medicina regenerativa, si bien tiene un largo trecho por transitar, constituye una realidad indiscutible. Esto no ha pasado inadvertido al mercado que, en el caso de las células, ha introducido la distinción entre "células naturales" y "células obtenidas por procedimientos técnicos". Esta distinción, tal como veremos, es el punto de partida para incorporarlas al mercado. A propósito de esta cuestión, resulta muy ilustrativa la posición del Comité Francés.

En el Dictamen $n^{\circ} 93$ del Comité Consultivo Nacional de Ética para las Ciencias de la Vida y la Salud de Francia ${ }^{13}$, se tocan los aspectos éticos de la investigación sobre células madre y su utilización. Comienza el dictamen por establecer una diferencia entre dos categorías: los productos de los cuerpos humanos separados y no transformados - por una parte - y los productos derivados del cuerpo humano - por la otra -. En función de ello, al referirse a las células, diferencia las naturales de las obtenidas gracias a procedimientos técnicos, in vitro, que por no ser asimilables a las naturales son patentables. Esta división, a mi juicio, es muy discutible.

Pretender asimilar una célula, por importante que sea la intervención humana sobre la misma, a un artefacto o a una composición de materia para tornarla patentable resulta arbitrario. La célula "transformada" no pierde su pertenencia al género de la vida. Cosa distinta sería extraer de la célula algún elemento de su composición para industrializarlo. A lo que se refiere el Dictamen no es a un producto de la célula ni a una parte, una vez que la célula fue destruida. Se trata de una célula "transformada" con mayor o menor intensidad.

Entendemos que por ello no pierde la esencia de lo humano y en consecuencia tal célula "transformada" debe estar fuera del comercio. Tanto las células naturales, en el decir del Comité, como las tratadas con procedimientos técnicos continúan siendo partes separadas del cuerpo humano. El día que el 
hombre sea capaz de crear células mediante procedimientos técnicos podrá revisarse esta opinión. Por ahora, en tanto no es posible lograrlo, deben quedar fuera del mercado en la medida que se acepte como principio rector el de la no comercialidad del cuerpo y sus partes.

El enfoque jurídico - enmarcado en los derechos de propiedad industrial - debe remitirnos al concepto de invención patentable para conceder o denegar una patente de invención respecto de células "derivadas" o "transformadas". Condición central para la adquisición del derecho de exclusiva que otorga una patente de invención es la existencia de una invención patentable, que se enuncia como creación humana, de carácter técnico, para solucionar un problema técnico. La "invención" sería patentable si además de ello reúne los denominados requisitos objetivos de patentabilidad, es decir si constituye el aporte de algo novedoso, que no existía con anterioridad; que el aporte técnico tenga una determinada altura o mérito que no lo haga ingresar en el género de lo obvio, y que al momento de la solicitud el "invento" sea aplicable industrialmente.

En el caso que nos ocupa, la célula humana preexistió a la denominada célula transformada. Por mucho que le haya adicionado tal "transformación", las células que resulten del procedimiento no deberían perder su condición de humanas, aun cuando el procedimiento de transformación haya tenido lugar in vitro. En la consideración de este tema debe entrar necesariamente la ineludible diferenciación entre lo vivo y lo artificialmente creado por el hombre.

Sobre este particular me remito al claro pensamiento de Duve, Premio Nobel de Medicina, quien sostiene que en la edificación de una casa los obreros construyen los planos dibujados por un arquitecto. En la construcción de una célula, ¿̇dónde están los obreros?, ¿dónde está el arquitecto? No los hay. Todo ello tiene lugar automáticamente, según estimaciones escritas en las moléculas implicadas. Lo extraordinario de estos fenómenos es su espontaneidad. Aunque puedan estar implicadas varios cientos de partes, desde el montaje de una estructura, todo ocurre sin intervención externa ${ }^{14}$.

Cabe aquí reflexionar que, si las células transformadas no conservaran la esencia de sus elementos constitutivos, el "inventor" no tendría necesidad de utilizarlas, ya que le bastaría con la creación ex nihilo de una "nueva célula". Lo que debe advertirse a esta altura de la exposición es que la división entre células naturales y células transformadas constituye un simple subterfugio para obtener un derecho de exclusiva (la patente), que a todas luces no se obtendría en caso contrario.

Tallacchini ${ }^{12}$, al referirse a la creación de productos elaborados a partir de materiales biológicos humanos, pero artificialmente transformados hasta el punto de ser calificados como construidos bio artificialmente (bio artificial constructs), productos bio ingenierizados (bio engineerized products), invenciones biológicas (biological inventions), considera que el principal problema relativo al cuerpo artefacto, consiste en evaluar si las biotecnologías alteran los materiales biológicos, hasta el punto de hacer que se los considere objetos artificiales, definibles como "inventos" ${ }^{12}$. Cabe aquí advertir que las biotecnologías, en mi entender, carecen de entidad como para transformar un elemento humano en un objeto artificial. Todo lo ligado a la vida es natural y por importante que sea la actuación del hombre sobre un "objeto natural", no puede conducir a que adquiera la categoría de "objeto artificial".

En el razonamiento que permite patentar elementos humanos "transformados" existe un doble circuito. Inicialmente, lo natural pasa a ser "artificial", cerrando el primero de ellos y luego lo "artificial" pasa a ser "patentable", cerrando el segundo. Para pasar al segundo circuito, debe existir una construcción que lo permita la distorsión del concepto de "invención patentable". La sola intervención del hombre, por más insignificante que fuera, es para esta concepción suficiente para permitir la patentabilidad.

A esto, ayuda la circunstancia de que la gran mayoría de las legislaciones, incluida la internacional (Acuerdo de los ADPIC de la OMC ${ }^{15}$ ), eluden definir la "invención"; lo que conduce a que conforme las circunstancias del caso una "invención" pueda consistir en el simple hecho de hallar un microorganismo en la naturaleza, segregarlo de su medio natural, con lo que se convierte en una "invención patentable". Esto es lo que sin mayor esfuerzo intelectual se deduce del artículo $3^{\circ}$ de la Directiva Europea sobre Protección de las Innovaciones Biotecnológicas ${ }^{16}$.

La invención patentable presupone una creación humana. Las necesidades de las empresas industriales han llevado a distorsionar el concepto de invención a límites inadmisibles. Así, la Corte Suprema estadounidense al resolver el caso Chakrabarty, consideró que el científico que había logrado modificar el metabolismo de una bacteria para dotarlo de determinadas características, habría "creado" un nuevo organismo, convirtiendo al hombre en una especie de Dios ${ }^{17}$. Más adelante, la referida opinión 
del Comité Francés de Bioética considera que según la manera con que definimos las entidades biológicas consideradas, el enfoque ético de la comercialización tiene una dirección diferente.

En esta línea de pensamiento, establece una diferencia entre un material biológico en estado bruto y una molécula química. A criterio del Comité, existen entre los dos una zona difícil de diferenciar entre la biología y la química. Esta zona comprende las entidades intermedias, productos biológicos, tratados de grado tal que han perdido parte de su estatuto biológico, por ejemplo las células, los productos de terapia celular, la bioingeniería de células y tejidos etc. Para tales entidades, agrega, la cuestión de saber si pueden ser consideradas como realidades biológicas o bien como especialidades farmacéuticas o medicamentos fabricados industrialmente, queda abierta. ¿A partir de cuándo se interrogarlos elementos celulares pueden ser considerados como suficientemente separados y diferenciados de cada uno para ser objeto de comercio? Todo lienzo de separación, todo criterio parece imposible de fijar. Por último algo que es evidente, un órgano no tiene la misma relación respecto del individuo que una célula o una molécula.

Interviene aquí un criterio relativo al grado de transformación del cual es objeto el material biológico con el fin de obtener las células que se desean. Una intervención mínima consistiría por ejemplo en acondicionar las células a los fines de conservación; una intervención máxima consistiría en obtener una célula mediante la transferencia de su núcleo. Entre las dos se ubica la mayor parte de las intervenciones de que son objeto las células. Pareciera que estamos ante un conflicto difícil de superar entre el derecho de propiedad industrial que pretende volcar su aporte a la apropiación de lo humano, y la biología que apunta a conservar la esencia de lo humano.

La visión diferente del derecho y de la medicina no es, según lo entiende Labrousse Riou, conflictiva. El conflicto surge de la utilización de los cuerpos tratados como cosas, su instrumentalización científica o médica, lo que provoca la "de subjetivación" de la persona y genera un mercado de la vida. Así el cuerpo deviene en materia prima, un objeto de consumo o de producción, lo que lleva a la autora a formular interrogantes cuya respuesta exige una profunda reflexión: ¿qué es el cuerpo para el derecho?; ¿cuál es la naturaleza de los derechos sobre el cuerpo? ; ¿los fines científicos o médicos justifican un derecho exorbitante? Lo que digamos sobre el cuerpo a esta altura de los tiempos cabe trasladarlo a sus partes separadas y a los productos ${ }^{18}$.
Cabe igualmente recordar que una célula puede ser tanto o más importante que cualquier material biológico, careciendo de sentido valorarla conforme a su tamaño. Una célula es de por sí un microcosmos y de su importancia nos habla la biología celular que hoy constituye uno de los pilares de la biología. La existencia de "zonas grises" entre las partes del cuerpo naturales y las partes transformadas que han perdido parte de su estatuto biológico ${ }^{12}$ constituye simplemente un recurso retórico para justificar el avance del mercado sobre lo humano.

La célula, en su insignificante tamaño, envuelve en sí parte de la evolución humana que aún en sus últimas manifestaciones nos sigue maravillando como una obra maestra que el hombre no ha podido crear por sus propios medios.

\section{Las células madre en el mercado}

En 1998 James Thomson ${ }^{19}$ y sus colaboradores consiguieron mediante un procedimiento original, aislar y cultivar células embrionarias humanas. Esto, al margen de importar un notable avance científico, despertó una notable controversia que va más allá del tema académico. Thompson solicitó y obtuvo los derechos de propiedad industrial sobre el procedimiento y los productos (incluidas las propias células madre); derecho que fue cedido a la Universidad de Wisconsin. Las patentes otorgadas abarcaban tanto las células madre como las principales técnicas utilizadas para desarrollarlas.

Ello permitió a la Wisconsin Alumni Research Foundation (WARF) prohibir a los investigadores reproducir, usar, vender, ofrecer a la venta o importar lo patentado, así como la utilización de la idea patentada como base para llegar a otra "invención". Los contratos de WARF - titular de los derechos con investigadores académicos incluyen limitaciones críticas referidas a los fines para los cuales podrían ser usadas las células madre. Utilizó preferentemente dos caminos para controlar el mercado de células madre embrionario humanas: licencias que rigen el uso del material patentado, sobre la base del pago de un honorario fijo; y regalías por la venta de cualquier producto derivado de la licencia. Dados los abusos cometidos, WARF ha sido acusada por la comunidad académica de "sofocar" el mercado de las células madre ${ }^{20}$.

Situación - en alguna forma similar - se presenta con las investigaciones de Yakamata y colaboradores de la Universidad de Kyoto ${ }^{21}$, relativas a las células pluripotentes inducidas que permitieron la 
reprogramación celular, lo que posibilitó la patentabilidad del método empleado así como de las células reprogramadas. Aquí se presentan dos temas en el campo ético:

1) el sometimiento a derechos privados de las células humanas y los procedimientos empleados para su cultivo, lo que importa incorporarlas al mercado como "producto patentable";

2) el serio obstáculo para la investigación científica que importa el establecimiento de barreras económicas difíciles de flanquear.

\section{Consideraciones finales}

A través de un caso concreto - el de la comercialización y patentabilidad de células y líneas celulares humanas - hemos pretendido mostrar algunas notas destacadas de un proceso en plena evolución llamado a transformar a los componentes del cuerpo humano en materia prima de la industria. Es este un proceso silencioso que no ha llegado a llamar mayormente la atención de la sociedad; pero que una vez consolidado estimo que será muy difícil de rever.

Aquí se encuentran comprometidos principios éticos que desde antiguo se han enunciado y se han admitido sin mayores disidencias, tal el de la no comercialidad del cuerpo humano y sus partes; construcciones jurídicas como las vinculadas a los límites de la patentabilidad; el estatuto de la investigación fundamental y la protección de la salud humana. En el plano ético si bien no se cuestiona la no comercialidad del cuerpo humano en su integridad, se establece una sustancial diferencia con relación a las partes separadas, que - consideradas simplemente como cosas - entran en el mercado.

En el plano jurídico la histórica y medular diferencia entre invento y descubrimiento se deja de lado, permitiendo conforme al interés de la industria la patentabilidad de hallazgos de ciencia básica que muy poco tienen que ver con las creaciones tecnológicas, campo de acción del derecho de la propiedad industrial ${ }^{22}$. De esta forma la esencial diferencia en- tre investigación básica e investigación aplicada entra en un cono de sombra que conforme al interés del caso posibilitará la apropiación de sus hallazgos.

Aplicar a los resultados de la investigación fundamental los instrumentos de protección por excelencia de la industria (las patentes) - anota Franceschi - no lo es sin consecuencias para la lógica interna de los derechos de propiedad industrial, ni para el devenir de la actividad investigadora. La relectura de las condiciones de patentabilidad en el sentido de otorgar al descubrimiento la calificación de invención, conduce a la ruptura del equilibrio organizado por el derecho de patentes ${ }^{23}$. La creciente categoría de "medicamentos biológicos" muestra asimismo una tendencia en cuyo desarrollo el cuidado y la protección de la salud humana pueden quedar bloqueados por el avance de las fuerzas del mercado. Estas no son postales del futuro, sino muestras de una realidad palpable que no podemos dejar de observar sin una creciente preocupación.

Hermitte, en un estudio sobre la comercialización del cuerpo humano y sus productos recuerda que el mundo occidental ha pasado rápidamente de una situación donde la idea de comercialización del cuerpo evocaba la esclavitud a una situación donde ello está ligado a los fabulosos progresos médicos o farmacológicos: sangre, órganos, sustancias, proteínas, enzimas, hormonas, anticuerpos, tejidos, material genético; todo puede ser utilizado a los fines médicos o científicos, así como puramente comerciales, haciendo del cuerpo humano una fuente de materia prima para la industria. Los puntos de contacto entre estas dos realidades distintas obligan a proceder con la mayor prudencia para evitar el retorno a formas de explotación que, por no ser menos violentas, no son menos atentatorias a la dignidad humana ${ }^{24}$.

El debate no puede quedar circunscripto a los derechos de propiedad industrial; sería un craso error que ello suceda. En la medida en que se encuentran comprometidos intereses de primer nivel como la salud humana, la libertad de investigación, la defensa irrestricta de la no comercialidad del cuerpo y sus partes separadas, deben comprometer nuestra atención y nuestros esfuerzos.

\section{Referências}

1. Rendtorff D. Principios básicos de la bioética y del derecho europeo. Perspect Bioét. 2000;5(9):74.

2. Kuhse H. II corpo como propietá, Ragioni di scambio e valore étici. In: Rodotá S. Questioni di bioética. Bari: Saggitari Laterza; 1993. p. 65.

3. France. Code Civil. [Internet]. [acesso abr. 2013]. Disponível: http://archive.equal-jus.eu/180/1/ Code_civil_1_eng.pdf 
4. Consejo de Europa. Convenio sobre los Derechos Humanos y la Biomedicina. [Internet]. Celebrado en Oviedo, España, el 4 de abril de 1997 [acesso out. 2012]. Disponivel: http://www.colmed2.org. ar/images/code04.pdf

5. Unión Européia. Carta de los Derechos Fundamentales de la Unión Europea. Diario Oficial de las Comunidades Europeas. [Internet]. 18 dez. 2000 [acesso out. 2012]:C364/1. Disponível: http:// www.europarl.europa.eu/charter/pdf/text_es.pdf

6. Sève L. Pour une critique de la raison bioéthique. Paris: Odile Jacob; 1994. p. 105.

7. France. Loi no $94-653$, du 29 juillet 1994. [Internet].Relative au respect du corps humain. Version consolidée au 30 juillet 1994 [acesso out. 2012]. Disponível: http://legifrance.gouv.fr/affichTexte. do?cidTexte=JORFTEXT000000549619

8. Rodotá S. La vida y las reglas. Madrid: Trota; 2010. p. 117.

9. Lewis W. Cómo vivimos, por qué morimos: la vida secreta de las células. Buenos Aires: Tusquets; 2011. p. 14

10. Edelman B. Ni chose ni personne: le corps humain en question. Paris: Herman Philosophie; 2009 p. 57.

11. Hermitte MA. Le corps hors du comerse, hors du marché. Archives de Philosophie du Droit. 1988;33:327.

12. Tallacchini M. El cuerpo y sus partes: la ubicación jurídica de los materiales biológicos humanos. Revista de Medicina y Ética (México). Ene-Mar. 1999;10(1):33-80.

13. France. Comité Consultatif National d'Etique pour les Sciences de la Vie et de la Santé. Avis $n^{\circ}$ 93. Commercialisation des cellules souches humaines et autres lignées cellulaires. 17 nov. 2006 [acesso out. 2012]. Disponível: http://www.orpha.net/actor/Orphanews/2006/doc/Avis_CCNE. pdf

14. Duve CD. La vida en evolución. Madrid: Editorial Crítica; 2004. p. 44.

15. Organizacion Mundial del Comercio. Declaración de Marrakech de 15 de abril 1994. Anexo 1C: Acuerdo sobre los Aspectos de los Derechos de Propiedad Intelectual Relacionados con El Comercio. [acesso out. 2012]. Disponível: http://www.wto.org/spanish/docs_s/legal_s/27-trips. pdf

16. Parlamento Europeu. Directiva 98/44/CE de 6 de julho de 1998. Relativa à protecção jurídica das invenções biotecnológicas. Artículo 3, inciso 2: la materia biológica aislada de su entorno natural o producida por medio de un procedimiento técnico podrá ser objeto de una invención, aun cuando ya existía anteriormente en estado natural - [acesso out. 2012]. Disponível: http://eurlex.europa.eu/LexUriServ/LexUriServ.do?uri=CELEX:31998L0044:PT:NOT

17. Bergel SD. La patentabilidad de seres vivos (a 30 años de Chakrabarty). La Ley. 25 mar. 2010$\mathrm{D}: 1269$.

18. Labrousse Riou C. Écrits de bioéthique. Paris: PUF; 2007. p. 133.

19. Thomson JA, Itskovitz-Eldor J, Shapiro SS, Waknitz MA, Swiergiel JJ, Marshall VS et al. Embryonic stem cell lines derived from human blastocysts. Science. 1998;282:1.145-7.

20. Bergman K, Graff G. The global stem cell patent landscape: implications for efficient technology transfer and commercial development. Nat Biotechnol. 2007;25(4):419-24.

21. Takahashi K, Tanabe K, Ohnuki M, Narita M, Ichisaka T, Tomoda K et.al. Induction of pluripotent stem cells from adult human fibroblasts by defined factors. Cell. 2007;131(5):861-72.

22. Bergel SD. Acerca de la patentabilidad de los descubrimientos. La Ley. 16 jun. 2009-C;82(112):1315

23. Franceschi M. Droit et marchandisation de la connaissance sur les gens humains. Paris: CNRS; 2004. p. 101

24. Hermitte MA. Comercialisation du corps et ses produits. In: Hottois G, Missa JN. Nouvelle encyclopédie de bioéthique. Brussels: De Boeck; 2001. p. 209.

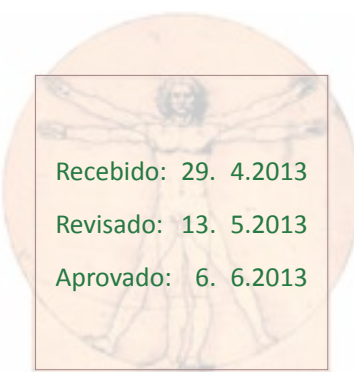

